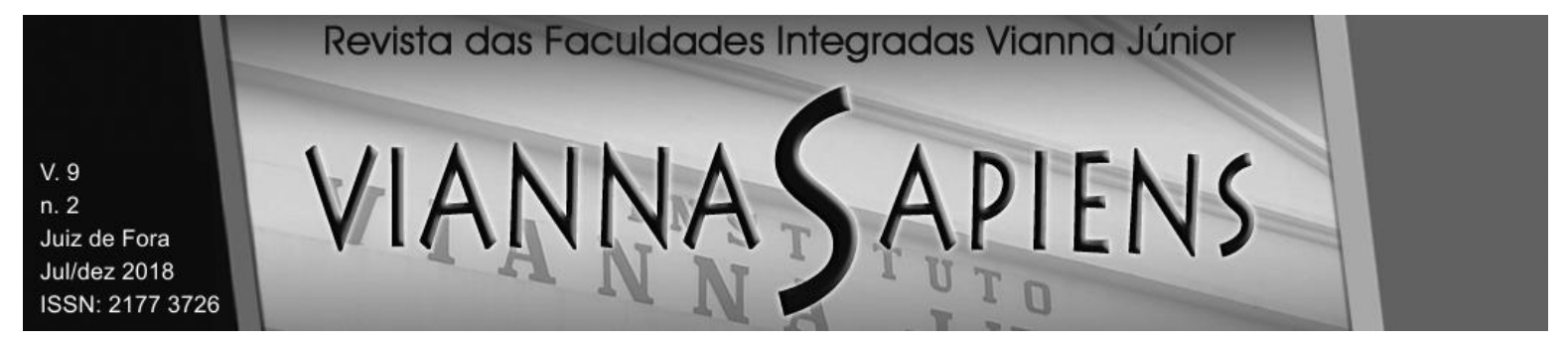

DIREITOS FUNDAMENTAIS APLICADOS AO DIREITO PRIVADO

DOI: 10.31994/rvs.v9i2.471

Rafael Pleutin Arakaki $^{1}$

Samya Abud ${ }^{2}$

\title{
RESUMO
}

O presente artigo possui o intuito de analisar a aplicação e efetividade dos Direitos Fundamentais nas relações entre particulares, onde se reconhece o Direito Privado. A reflexão abrigará conceitos e evolução histórica dos Direitos Fundamentais e se desenvolverá a luz do direito comparado, demonstrando que a eficácia horizontal dos Direitos Fundamentais, ainda que de forma não expressa, é adotada pelo Brasil de forma direta, a partir da interpretação e hermenêutica constitucional. Ao final, conclui-se que os Direitos Fundamentais preenchem lacunas deixadas pelos legisladores, e que a sua não aplicação afetaria de forma substancial a preservação da dignidade da pessoa humana. A metodologia adotada é a bibliográfica e documental.

PALAVRAS-CHAVE: EFETIVIDADE. EFICÁCIA HORIZONTAL. DIREITOS FUNDAMENTAIS.

\footnotetext{
${ }^{1}$ Especialista em Direito Processual Civil pela PUC-SP, professor no curso de Direito da Faculdade Campo Grande, e-mail: adv.rafarakaki@gmail.com, ORCID: https://orcid.org/0000-0002-2394-0228. ${ }^{2}$ Doutoranda em Desenvolvimento Local pela UCDB, professora e coordenadora no curso de Direito da Faculdade Campo Grande, e-mail: samya abud10@hotmail.com, ORCID: https://orcid.org/00000002-8826-5067
} 


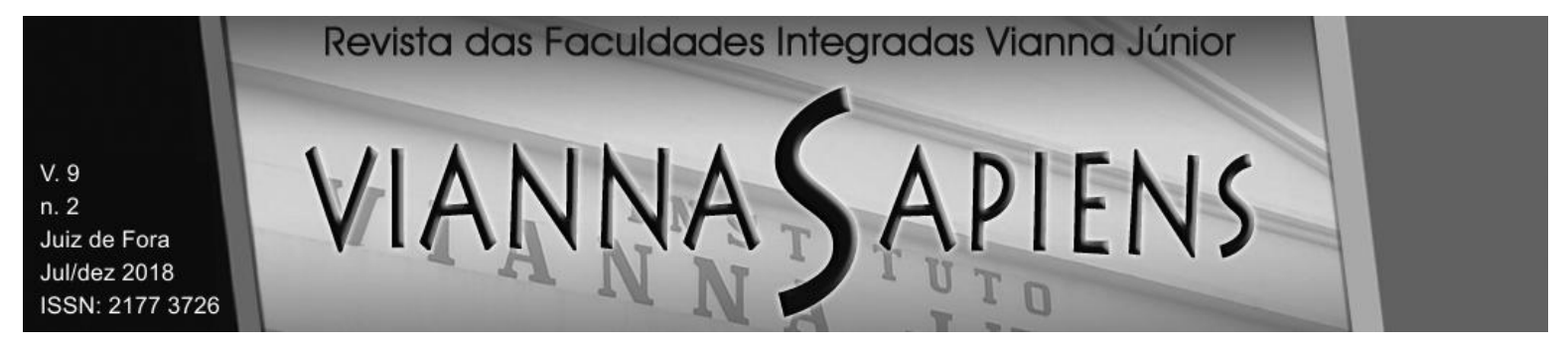

FUNDAMENTAL RIGHTS APPLIED TO PRIVATE LAW

\begin{abstract}
The purpose of this article is to analyze the application and effectiveness of Fundamental Rights in relations between private individuals, where private law is recognized. The reflection will shelter concepts and historical evolution of Fundamental Rights and will develop the light of comparative law, demonstrating that the horizontal efficacy of Fundamental Rights, although in an unexpressed form, is adopted by Brazil directly, based on constitutional interpretation and hermeneutics . In the end, it is concluded that fundamental rights fill gaps left by legislators, and that their non-implementation would substantially affect the preservation of the dignity of the human person. The methodology adopted is bibliographical and documentary.
\end{abstract}

KEYWORDS: EFFECTIVENESS. HORIZONTAL EFFICACY. FUNDAMENTAL RIGHTS.

\title{
INTRODUÇÃO
}

Este estudo tem por objetivo analisar a relação entre direitos fundamentais e os direitos privados com base nas teorias da eficácia horizontal dos Direitos Fundamentais.

Analisar-se-á primeiramente o conceito de Direitos Fundamentais bem como a evolução histórica que é fundamental para a compreensão de quem seriam os destinatários ou sujeitos de tais direitos.

Após, investiga-se acerca das dimensões e classificações dos Direitos Fundamentais, aprofundando nos motivos que induziram seu aprimoramento e resultaram na incorporação Constitucional atual. 


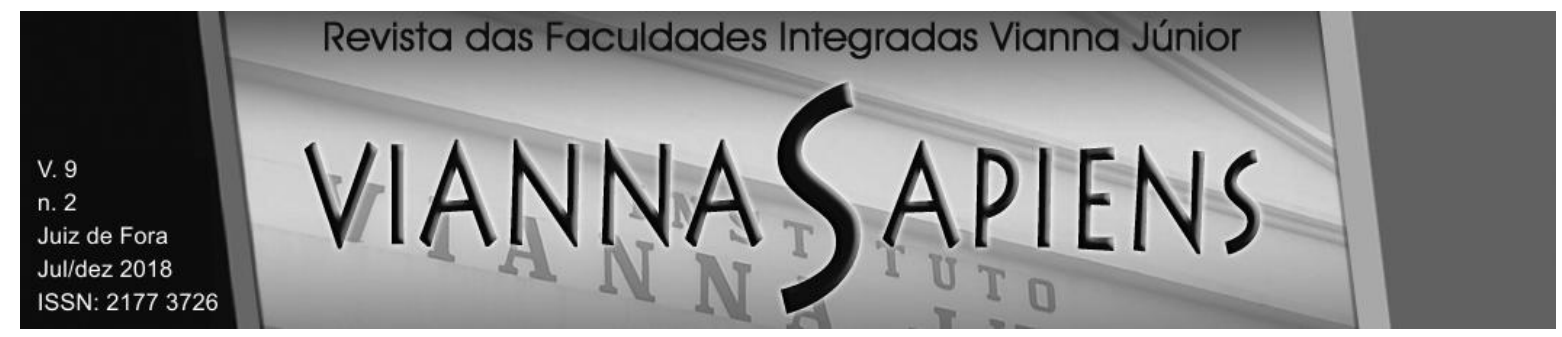

Em seguida, verifica-se a possibilidade de aplicação dos Direitos Fundamentais nas relações entre particulares tanto de forma direta como indireta, provida pelo Estado.

Por fim, analisa-se os benefícios de tais aplicações que rompem com um conceito clássico, de que Direitos Fundamentais seriam apenas oponíveis ao estado, não sendo possível sua aplicação no direito privado. Trazendo por consequência a problemática acerca da finalidade dos Direitos Fundamentais, bem como possíveis ofensa ao princípio constitucional da autonomia da vontade.

Ademais, traz à baila uma reflexão sobre a forma como esses Direitos Fundamentais devem ser impostos, uma vez adotados nas relações entre particulares. Se de forma direta, aplicando-se o texto Constitucional ao caso concreto, ou de forma indireta, aguardando-se uma lei infraconstitucional que regulamente.

Tais indagações são matérias de discussão tanto no Brasil como em Portugal, posto isso, analisar-se-á da perspectiva constitucional e jurisprudencial em ambos os países, utilizando-se da metodologia bibliográfica e documental.

\section{CONCEITO DE DIREITOS FUNDAMENTAIS}

Antes de iniciar a reflexão sobre a aplicação dos Direitos Fundamentais nas relações entre particulares, cabe destacar o conceito destes direitos, bem como o contexto histórico onde foram introduzidos no ordenamento jurídico.

Segundo Canotilho (2002, p.194):

[...] os direitos fundamentais em sentido próprio são, essencialmente direitos ao homem individual, livre e, por certo, direito que ele tem frente ao Estado, decorrendo o caráter absoluto da pretensão, cujo o exercício não depende de previsão em legislação infraconstitucional, cercando-se o direito de diversas garantias com força constitucional, objetivando-se sua imutabilidade jurídica e política. (...) direitos do particular perante o Estado, essencialmente direito de autonomia e direitos de defesa. 


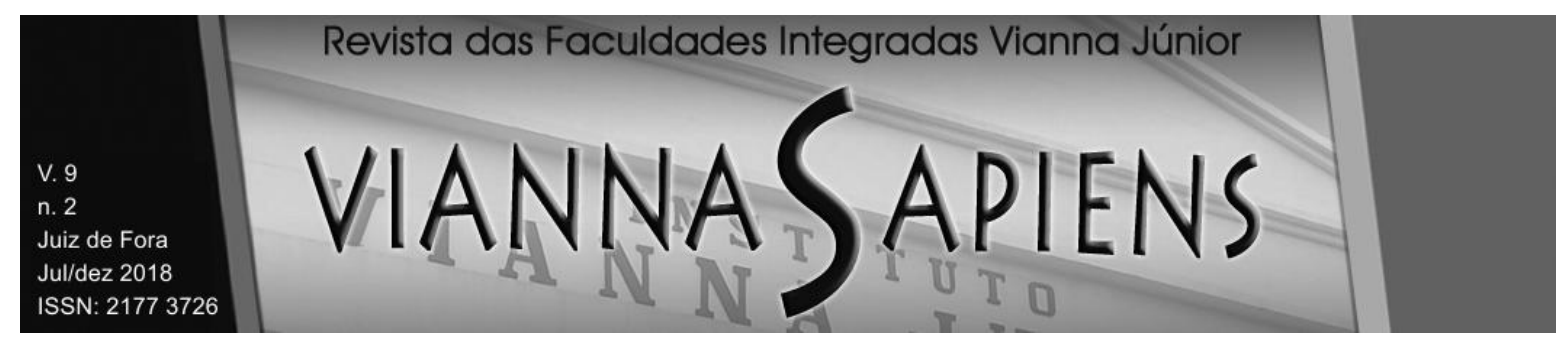

Verifica-se a partir de tal concepção que a luta do homem pela garantia dos direitos fundamentais teve início há séculos, quando uma das primeiras conquistas das liberdades mínimas foi a clamada Magna Carta, conferida na Inglaterra de 1215 pelo Rei João Sem Terra. A partir deste marco, foi na própria Inglaterra que a igualdade civil e a liberdade política se proliferaram pelo mundo como condição essencial à vida social.

Séculos após, os Direitos Fundamentais ganharam um contorno universal, com a Declaração dos Direitos do Homem e do Cidadão, priorizando princípios e garantias individuais que influenciaram e permanecem influenciando as constituições contemporâneas.

Posto isso, para se alcançar o conceito de Direitos Fundamentais supracitado, é preciso observar que estes são frutos de um processo histórico e estão em pleno desenvolvimento. Nessa mesma linha de raciocínio, Perez Luño citado por José Afonso da Silva (2003, p. 175) ressalta que:

\footnotetext{
Podemos entender direitos fundamentais, numa perspectiva atual, como o conjunto de faculdades e instituições que, em cada momento histórico, concretizam as exigências da dignidade, liberdade e igualdade humanas, as quais devem ser reconhecidas positivamente pelos ordenamentos jurídicos a nível nacional e internacional.
}

Todos os conceitos foram frutos de demandas humanas históricas que só foram verificadas a partir de uma análise do contexto histórico, demonstrando assim que os Direitos Fundamentais evoluíram com o tempo, não apenas acrescentando Direitos ao homem, mas também ampliando a sua aplicação nas relações intersociais. 


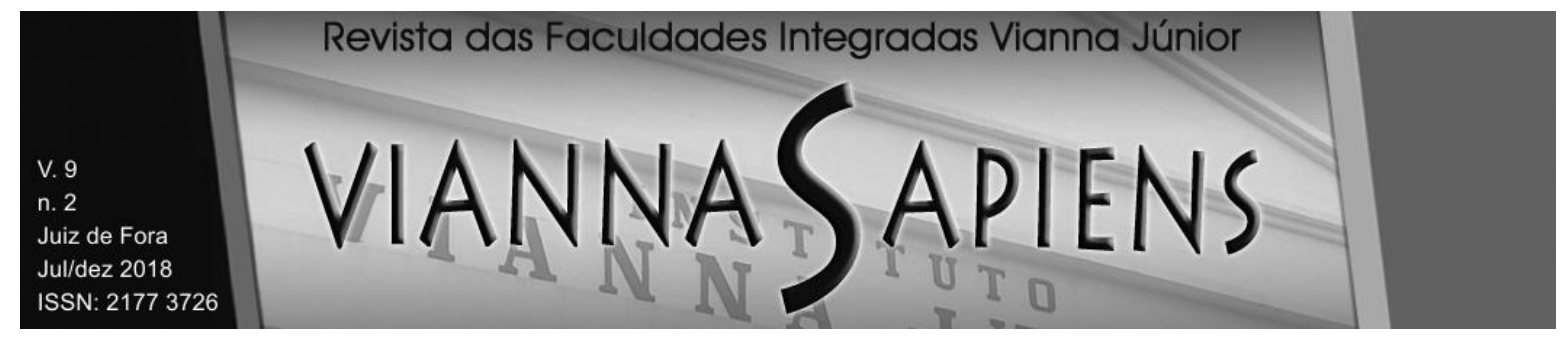

\section{SUJEITOS DOS DIREITOS FUNDAMENTAIS}

\subsection{Sujeitos Ativos}

A princípio é fato que os direitos fundamentais foram incorporados para serem rogados em favor de qualquer pessoa humana (pessoa física ou natural). Porém, interpretando superficialmente o caput do artigo $5^{\circ}$ da Constituição de 1988 verificase uma restrição de titularidade ativa dos direitos fundamentais, direcionando os mesmos aos " brasileiros" e aos " estrangeiros residentes no País". Inicialmente, é preciso interpretar extensivamente o conceito de residência, de tal forma que alcance todo estrangeiro que resida no Brasil, ainda que temporariamente, inclusive o que se encontrar em situação irregular no país. Em segundo lugar, é preciso discernir se estrangeiros não residentes como turistas, por exemplo, podem gozar da proteção dos direitos fundamentais, perante a literalidade do caput do art. $5^{\circ}$.

No Brasil, tanto a doutrina majoritária com base em reiterados entendimentos jurisprudenciais, adotam a corrente ampliativa de resguardar a dignidade da pessoa humana, sustentando a desconsideração da literalidade do preceito constitucional, sem outras ressalvas que não aquelas inerentes à especificidade da disciplina constitucional de cada direito fundamental.

Este foi o posicionamento do Supremo Tribunal Federal: ${ }^{3}$

O súdito estrangeiro, mesmo aquele sem domicílio no Brasil, tem direito a todas as prerrogativas básicas que the assegurem a preservação do status libertatis e a observância, pelo Poder Público, da cláusula constitucional do due process. O súdito estrangeiro, mesmo o não domiciliado no Brasil, tem plena legitimidade para impetrar o remédio constitucional do habeas corpus, em ordem a tomar efetivo, nas hipóteses de persecução penal, o direito subjetivo, de que também é titular, à observância e ao integral respeito, por parte do Estado, das prerrogativas que compõem e dão significado à cláusula do devido processo legal. A condição jurídica de não nacional do Brasil e a circunstância de o réu estrangeiro não possuir

\footnotetext{
${ }^{3}$ BRASIL. Supremo Tribunal Federal. Segunda turma. Embargos de declaração HC 94.016/SP. Relator: Min. Celso de Mello. 4/04/2009
} 


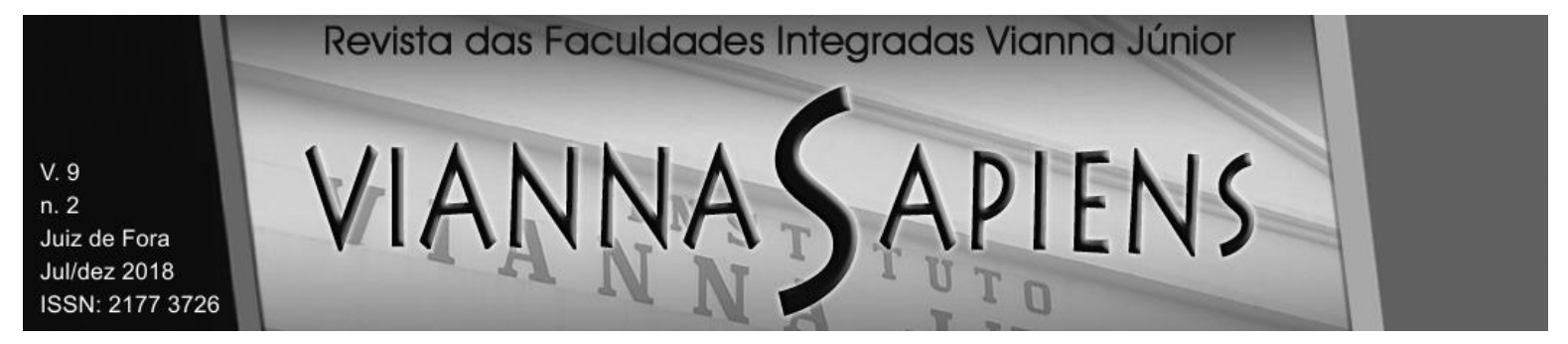

domicílio em nosso País não legitimam a adoção, contra tal acusado, de qualquer tratamento arbitrário ou discriminatório. (2 $2^{\mathrm{a}}$ Turma, HC 94.016/SP).

No tocante as pessoas jurídicas, é pacífico, que as mesmas também contem com a proteção do catálogo de direitos fundamentais equiparando-se às físicas, desde que, o exercício do direito em questão se compatibilize com as peculiaridades da pessoa jurídica.

\subsection{Sujeitos Passivos}

Historicamente, os direitos fundamentais foram concebidos para fazer frente a atuação abusiva de órgãos ou agentes estatais. Desta forma, da perspectiva estatal, a norma definidora de Direitos Fundamentais constitui-se numa norma de "competência negativa", restringindo as possibilidades de atuação dos órgãos do Estado.

Ainda que a definição supracitada esteja atrelada às entidades estatais, (tal como a garantia de irretroatividade da lei), muitos deles têm aplicação naturalmente direcionada às relações privadas (os direitos trabalhistas, por exemplo), havendo ainda outros oponíveis contra todos (erga omnes), como os direitos de propriedade, de personalidade, de sigilo das comunicações telefônicas.

A construção dos sujeitos ativos e passivos de Direitos Fundamentais foram realizadas com o tempo, tendo a doutrina optado por nomenclaturas como gerações e dimensões dos Direitos Fundamentais. Tal divisão histórica é de fundamental importância para melhor compreensão deste processo de sedimentação de direitos.

\section{DIMENSÕES DOS DIREITOS FUNDAMENTAIS}

Os Direitos Fundamentais da primeira dimensão, marcam o momento de passagem de um estado autoritário para um Estado de Direito. 


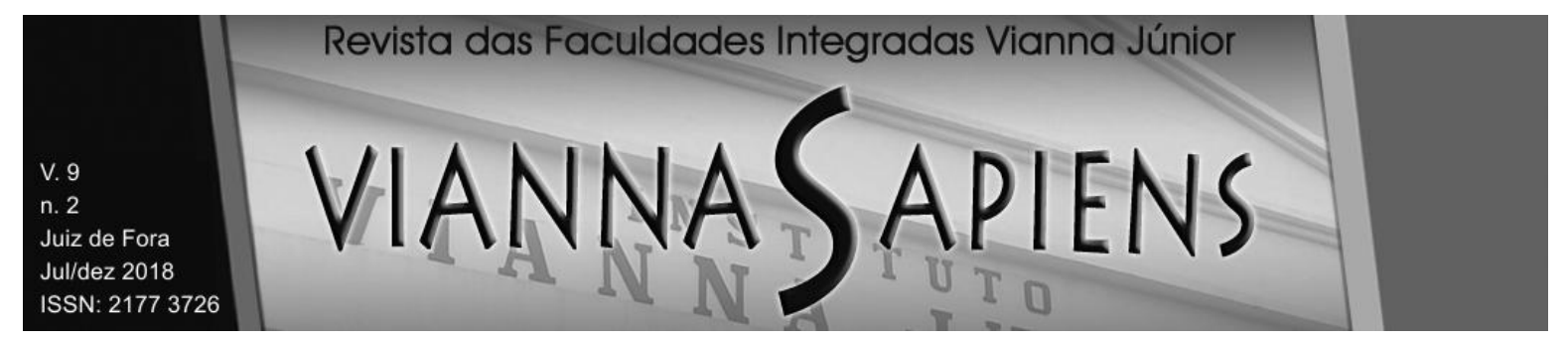

Segundo Bonavides (2010, p. 263):

Os direitos de primeira geração ou direitos de liberdades têm por titular o indivíduo, são oponíveis ao Estado, traduzem-se como faculdades ou atributos da pessoa e ostentam uma subjetividade que é seu traço mais característico; enfim, são direitos de resistência ou de oposição perante o Estado.

Os Direitos fundamentais de segunda dimensão tiveram como fato histórico impulsionador a Revolução Industrial Europeia a partir do século XIX, quando movimentos como o cartista, na Inglaterra e a Comuna de Paris iniciaram reinvindicações em prol das melhorias de condições de trabalho. A partir deste momento, iniciou-se a evidenciação dos direitos sociais, culturais e econômicos, bem como dos direitos de coletividade que correspondem aos direitos de igualdade material e não meramente formal.

Encerrando as dimensões clássicas dos Direitos Fundamentais, depara-se com a terceira dimensão, marcada por notáveis mudanças na comunidade internacional principalmente nas relações econômico-sociais.

Novos problemas e preocupações mundiais surgem, tais como a extrema necessidade de preservação ambiental e as dificuldades para a proteção dos consumidores, inserindo assim o ser humano numa coletividade. Por este motivo, tais direitos também recebem a denominação de transindividuais, ou seja, estão além do interesse do indivíduo.

A doutrina moderna, por orientação de Paulo Bonavides (2006, p. 571), posiciona-se pela existência da quarta dimensão dos Direitos Fundamentais, que decorreria dos avanços no campo da engenharia genética e da "globalização política na esfera da normatividade jurídica" responsável por introduzir a quarta geração.

A explanação destas dimensões é fundamental para melhor entendimento da evolução histórica dos Direitos Fundamentais, bem como as características que os mesmos foram obtendo com o passar dos tempos. 


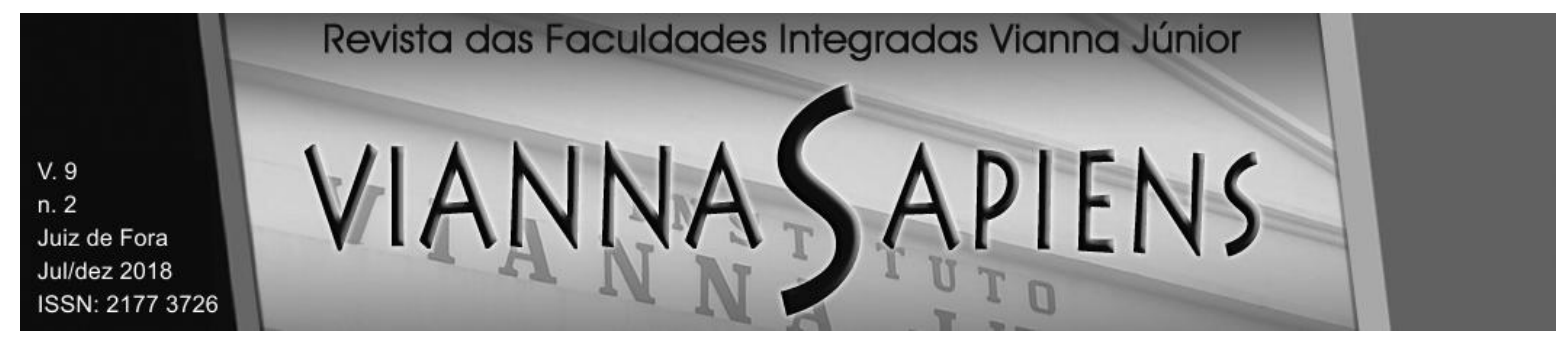

\section{CLASSIFICAÇÃO DOS DIREITOS FUNDAMENTAIS}

A doutrina classifica o desenvolvimento dos direitos fundamentais com 0 passar dos anos, a partir das diversas constituições que os incorporou.

$\mathrm{Na}$ constituição Federal da República Federativa do Brasil, os Direitos fundamentais possuem a seguinte classificação: Direitos Individuais (art. 5o); Direitos Coletivos (art. 5o); Direitos Sociais (arts. 6o e 193); Direitos à Nacionalidade (art. 12) e Direitos Políticos (arts. 14 a 17).

Por outro lado, a Constituição da República Portuguesa de 1976, classifica os direitos fundamentais como "situações jurídicas fundamentais das pessoas" reconhecidas nos artigos 24 a 79 da Constituição ou que sejam como tais admitidas na lei fundamental (por força dos artigos 16 e 17 da Constituição). Os direitos, liberdades e garantias são, formalmente, aqueles previstos nos artigos 24 a 57 da Constituição (título II da parte I, capítulos I, II e III da parte 1).

Apesar dessas perspectivas de classificação legislativa apresentadas, há outras classificações dos Direitos fundamentais que chamam a atenção como a de Jellinek que citado por José Carlos Vieira de Andrade (2001, p. 282) divide os Direitos Fundamentais em três espécies: sendo eles direitos de defesa, direitos prestacionais e direitos de participação.

Os Direitos de defesa caracterizam-se por defender o indivíduo dos atos arbitrários do Estado. Também são reconhecidos como direitos individuais clássicos, pois tiveram seu início visando a garantira da liberdade. Desta forma, tais direitos possuem um status negativo, pois reclamam do Estado uma abstenção, impondo ao próprio, o dever de não reprimir, censurar, intervir, etc...

Os Direitos Prestacionais, por sua vez, diferentemente dos direitos de defesa, exigem do estado uma atuação positiva, por meio de prestações jurídicas, como segurança, assistência judiciária gratuita, saúde, educação, políticas sociais, onde o estado possui o dever de prestar ao cidadão uma contrapartida positiva, visando o melhoramento da vida em sociedade. 


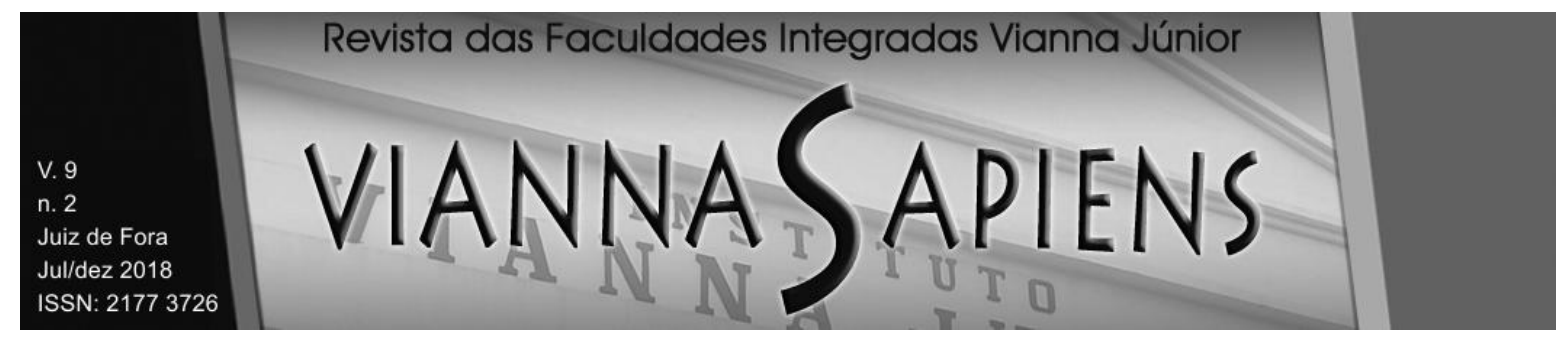

Por fim, os direitos de participação estão ligados diretamente à participação do indivíduo na política estatal. Ou seja, estão ligados à cidadania, que tem por função primordial garantir a participação individual na formação política da comunidade. Direito este fundamental para a formação democrática do estado de Direito.

\section{EFICÁCIA DOS DIREITOS FUNDAMENTAIS}

Após a devida conceituação, classificação e evolução histórica dos Direitos Fundamentais, adentraremos na possibilidade de aplicação dos mesmos nas relações entre particulares, também conhecido como eficácia horizontal dos Direitos Fundamentais.

Tal reflexão é essencial tendo em vista que os Direitos Fundamentais, a partir de uma interpretação clássica tem como único destinatário o Estado. Tal interpretação remete a eficácia vertical dos Direitos Fundamentais de origem na primeira dimensão/geração, ou seja, com base em direitos que limitam a atuação dos governantes frente as liberdades individuais dos governados.

Nesse contexto supracitado, o Estado deveria reduzir ao mínimo sua atuação para que a sociedade pudesse se desenvolver de forma harmoniosa. Concluindo assim, conforme Daniel Sarmento (2010, p.13) que estado e sociedade faziam parte de dois universos completamente diferente sem qualquer comunicação.

Esta conceituação clássica deu lugar a novos entendimentos onde as normas que estabelecem direitos fundamentais, se podem ser subjetivadas, não pertinem somente ao sujeito, mas sim a todos aqueles que fazem parte da sociedade.

Desta forma, é possível entender que a além do respeito aos direitos fundamentais imposta ao estado, o mesmo tem a obrigação de fazer com que particulares o respeitem, seja por meio de normas de proibição ou de imposição de condutas. 


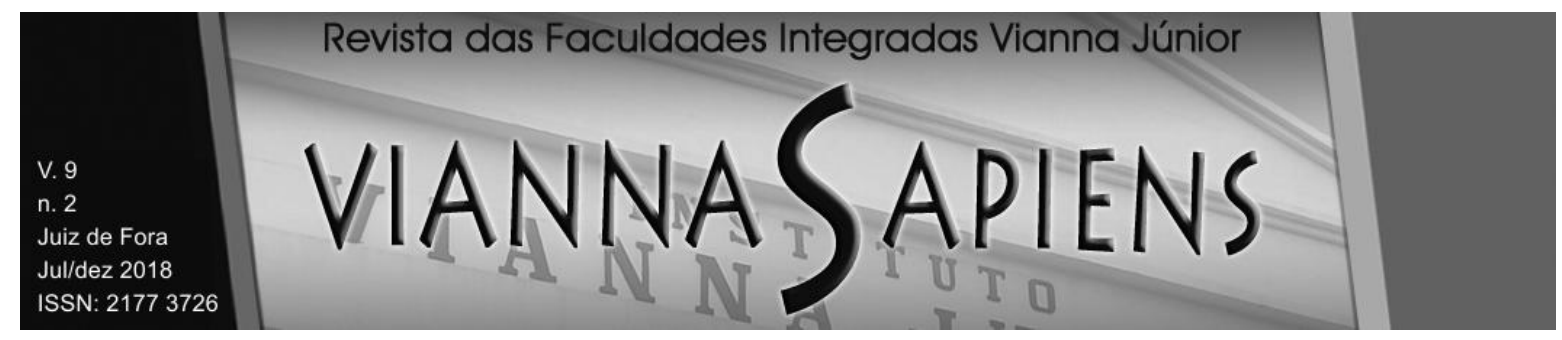

Tal intervenção estatal na aplicação dos Direitos Fundamentais sugerem uma aplicação indireta, que será melhor analisada no tópico à seguir.

\subsection{Teoria Da Eficácia Horizontal Indireta Dos Direitos Fundamentais}

$\mathrm{Na}$ doutrina de inspiração alemã, existem dois posicionamentos importantes acerca da aplicabilidade direta ou indireta dos direitos fundamentais em plano horizontal.

Seguindo o entendimento de Juliano Taveira Bernardes e Olavo Augusto Vianna Alves Ferreira (2015), com relação a aplicação indireta dos direitos fundamentais, a mesma parte do entendimento de que o Estado deve proteger os particulares uns dos outros por meio de lei. Ou seja, ainda que o conteúdo legal esteja vinculado a Constituição, e mesmo que a interpretação do direito privado seja conforme os direitos fundamentais, os mesmos não deveriam gerar reflexos diretos nos atos e negócio jurídicos privados, pois os particulares a princípio, não seriam os verdadeiros destinatários.

Nesse sentido, os direitos fundamentais só teriam aplicabilidade ao direito privado quando não houvesse normas jurídico-privadas, forçando desta forma o uso da interpretação e integração das cláusulas gerais do direito de acordo com os direitos fundamentais.

Em acordo com este entendimento, os direitos fundamentais não teriam a função de resolver conflitos de direito privado, devendo a aplicação realizar mediante os meios que o próprio sistema jurídico colocasse a disposição. Em outras palavras, os Direitos Fundamentais podem ser aplicados nas relações particulares, no entanto, é necessária uma intermediação través da lei, que por sua vez requisita uma atuação positiva do estado.

Segundo Cristiane Paglione Alves (2018):

A lei, o direito privado, teria que regulamentar, que incorporar aqueles direitos fundamentais ao direito privado, para que a 


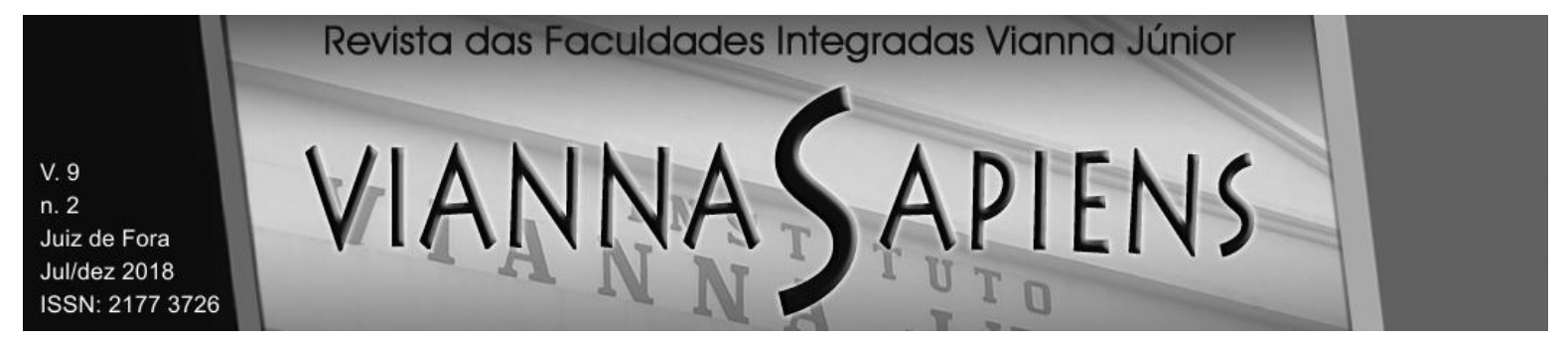

aplicação fosse relativizada, ou, tecnicamente falando, os direitos fundamentais irradiam os seus efeitos nas relações entre particulares por meio de mediação legislativa. Então, segundo a doutrina alemã, essa porta de entrada dos direitos fundamentais nas relações entre particulares seriam as cláusulas gerais do direito privado, os pontos de infiltração.

Portanto, para a teria da eficácia indireta os Direitos Fundamentais não são autoaplicáveis nas relações entre particulares, necessitando assim, do reforço positivo da lei por meio da atuação estatal.

\subsection{Eficácia Horizontal Direta dos Direitos Fundamentais}

A teoria da Eficácia horizontal direta ou imediata dos Direitos Fundamentais é a que representa a aplicação dos Direitos Fundamentais às relações privadas.

Segundo Ingo Wolfgand Sarlet (2006) existem dois aspectos que devem ser analisados quanto a este tema, sendo eles apresentados a seguir. Primeiro, quando existe uma certa igualdade das partes da relação jurídica, quando devem prevalecer o princípio da liberdade para ambas, somente se aceitando eficácia direta dos direitos fundamentais na possibilidade de lesão ou ameaça ao princípio da dignidade da pessoa humana ou aos direitos da personalidade. Segundo, quando a relação privada ocorre entre um indivíduo (ou grupo de indivíduos) e os detentores de poder econômico ou social, caso onde será admitiria a aplicação imediata tendo em vista que esta relação se assemelharia àquela que se estabelece entre os particulares e o poder público.

Nesse sentido, se verifica que o problema se resume na aplicação das limitações constitucionais em confronto com o princípio constitucional da autonomia privada. Pela teoria da eficácia direta, a autonomia privada não seria atingida diretamente pelas normas de direitos fundamentais que visam disciplinar relações e envolver entidades estatais. Por outro lado, a autonomia privada com base na teoria da aplicação indireta pode ser atenuada pela aplicação direta de outros direitos 


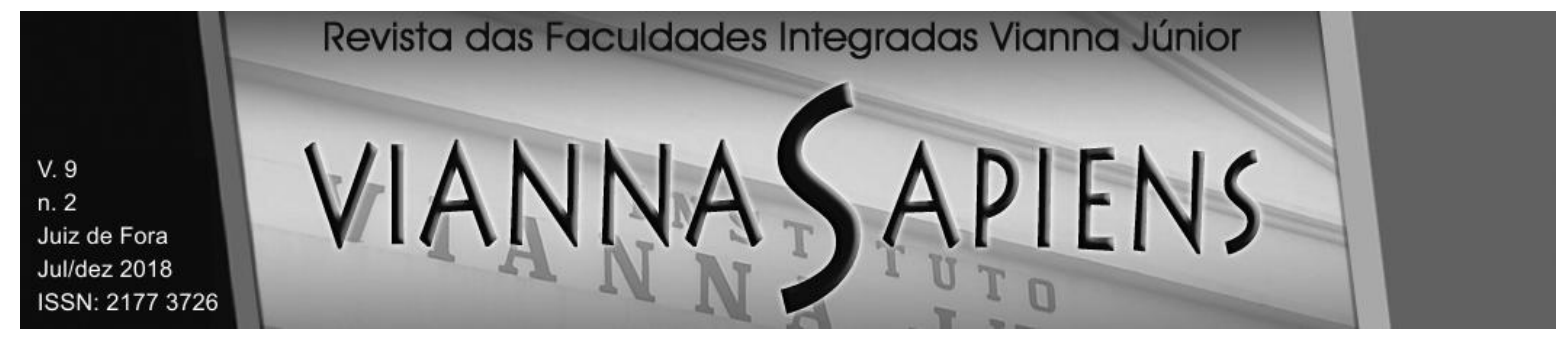

fundamentais, contudo, sua prevalência será mais forte quanto mais próxima se relacionar a direitos de ordem personalíssima.

\section{APLICAÇÃO DOS DIREITOS FUNDAMENTAIS NAS RELAÇÕES PRIVADAS EM PORTUGAL}

A Constituição Portuguesa de 1976 determina que "os preceitos relativos aos direitos, liberdades e garantias são diretamente aplicáveis e vinculam as entidades públicas e privadas". Segundo Alexandrino (2007) a aplicabilidade de forma direta imposta pelo artigo $18^{\circ}, n^{\circ} 1$, adviria primeiramente da necessidade de vinculação das normas ligadas aos direitos de liberdade, e em segundo, do fato de que o conteúdo de certos direitos fundamentais se encontra configurados na Constituição de forma imediata.

Nesse sentido, conclui-se que se as normas se aplicam diretamente, os cidadãos podem invocá-las imediatamente para resguardar seus direitos.

Conforme o entendimento de Karina Amaral (2010, p.10)

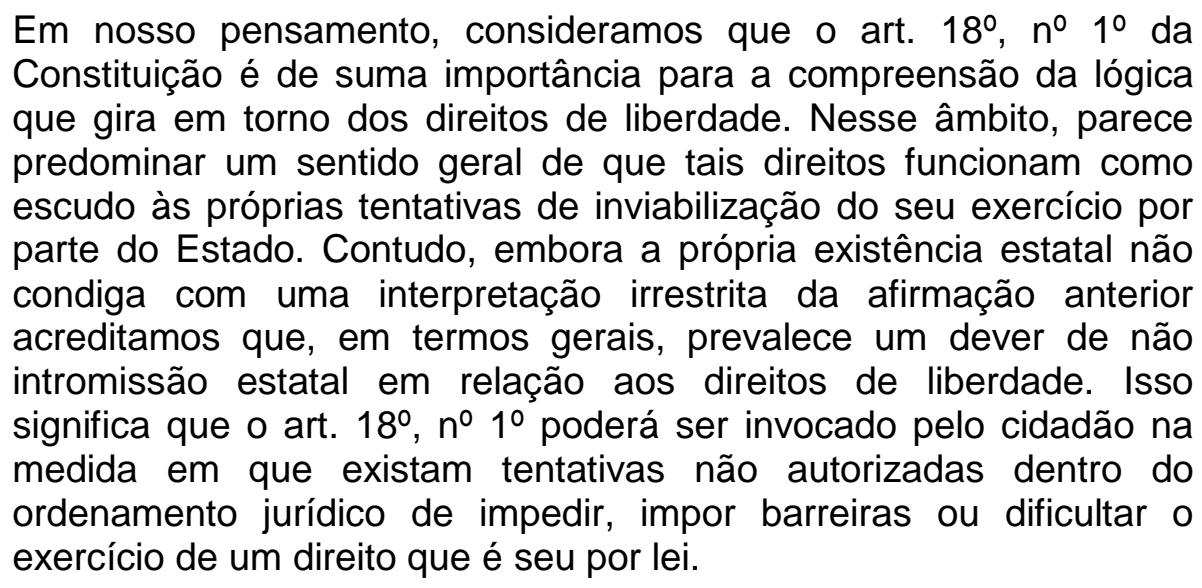

Conforme se verifica na parte final do referido artigo, os direitos, liberdades e garantias vinculam as entidades públicas e privadas. 


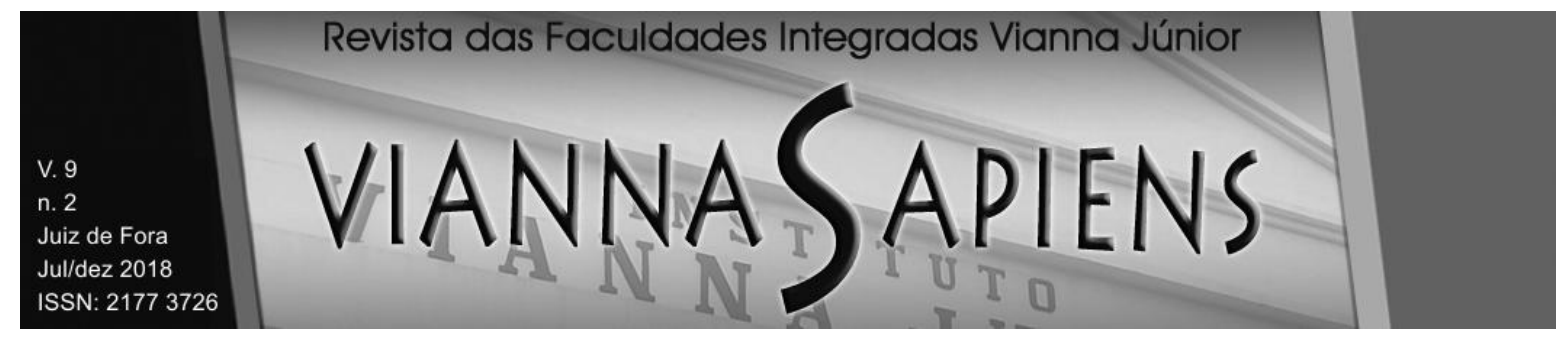

A discussão na Constituição Portuguesa não se respalda não possibilidade ou não da aplicação dos direitos fundamentais aos particulares, tendo em vista previsão expressa no artigo supracitado, mas sim acerca da aplicação direta ou indireta já citada em tópico anterior.

Como o posicionamento da eficácia direta ou indireta já foram expostos, cabe ressaltar por fim, os modelos dos deveres de proteção. O Estado deve respeitar os preceitos relativos às liberdade e garantias, possibilitando condições para a realização dos mesmos. Contudo, o Estado deve proteger o particular contra os próprios particulares, nas hipóteses de abuso de direito.

Apesar da clara necessidade de aplicação dos Direitos Fundamentais nas relações privadas, o autor Sarlet (2006, p.74) alerta para os possíveis conflitos de Direitos Fundamentais da seguinte forma:

Não é a existência de uma situação de "poder privado" ou de desigualdade na relação entre particulares que irá alterar o caráter jurídico-privado da relação jurídica em causa, nem afastar a circunstância de que, em última análise, estamos - também aqui diante de uma relação entre dois titulares de direitos fundamentais, já que, à evidência, também o particular ou entidade detentor de certo grau (por maior que seja) de poder social, não deixa de ser titular de direitos fundamentais. Assim, também nas relações deste tipo não se poderá deixar de reconhecer a existência de um conflito de direitos fundamentais, tornando-se indispensável uma compatibilização (harmonização) à luz do caso concreto, impedindo um tratamento idêntico ao das relações particular Poder Público.

\section{APLICAÇÃO DOS DIREITOS FUNDAMENTAIS NAS RELAÇÕES PRIVADAS NO BRASIL}

Diferentemente da Constituição Portuguesa que tem uma previsão expressa em sua constituição para a aplicação de Direitos Fundamentais nas relações entre particulares, o Brasil possui apenas entendimentos doutrinários e jurisprudenciais que são favoráveis a tal aplicação. 


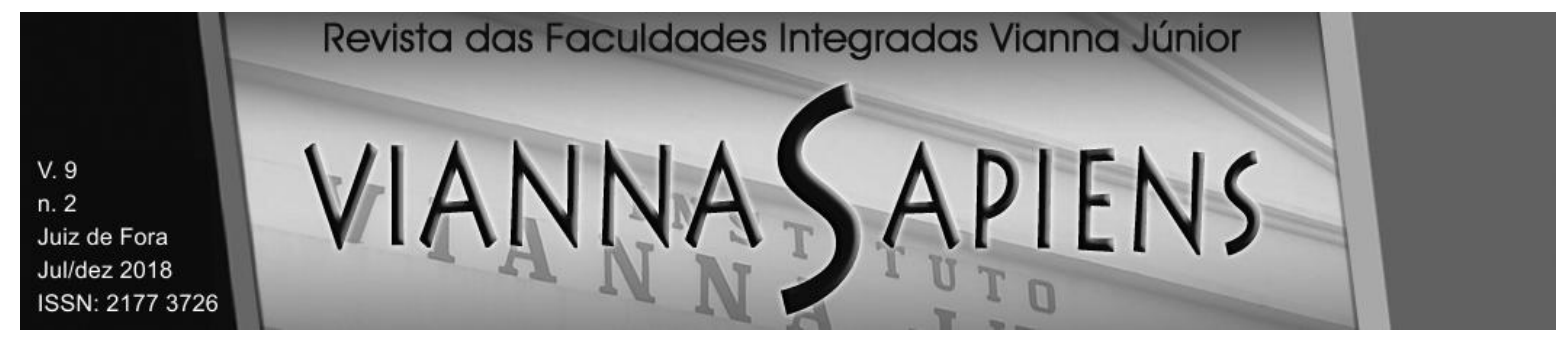

A desigualdade social no Brasil é latente, não permitir a aplicação dos direitos fundamentais nas relações entre particulares seria inaceitável. Afinal, quanto maior a desigualdade nas relações, maior a necessidade de proteção, posto isso, a teoria da eficácia horizontal direta no caso da realidade brasileira, é sem dúvida alguma a mais adequada.

Segundo Pedro Lenza (2009, p.667),

[...] poderá o magistrado deparar-se com inevitável colisão de direitos fundamentais, quais sejam, o princípio da autonomia da vontade privada e da livre iniciativa de um lado (CF, arts. 1ำ, IV, e 170, caput) e o da dignidade da pessoa humana e da máxima efetividade dos direitos fundamentais (art. $1^{\circ}$, III) de outro. Diante dessa 'colisão', indispensável será a 'ponderação de interesses' à luz da razoabilidade e da concordância prática ou harmonização. Não sendo possível a harmonização, o Judiciário terá que avaliar qual dos interesses deverá prevalecer.

O Supremo Tribunal Federal ${ }^{4}$ tem adotado, a eficácia horizontal dos Direitos Fundamentais, fundamentando da seguinte forma:

[...] A autonomia privada, que encontra claras limitações de ordem jurídica, não pode ser exercida em detrimento ou com desrespeito aos direitos e garantias de terceiros, especialmente aqueles positivados em sede constitucional, pois a autonomia da vontade não confere aos particulares, no domínio de sua incidência e atuação, o poder de transgredir ou de ignorar as restrições postas e definidas pela própria Constituição, cuja eficácia e força normativa também se impõem, aos particulares, no âmbito de suas relações privadas, em tema de liberdades fundamentais.

Assim, pode-se concluir que a aplicação da Teoria da Eficácia Horizontal por meio da ponderação de valores nas disputas geradas entre particulares é a tese que tem prevalecido no ordenamento jurídico brasileiro, onde encontra-se poucas divergências.

\footnotetext{
${ }^{4}$ (STF-RE 201819/RJ, rel. Min. ELLEN GRACIE, rel. p/ acórdão Min. GILMAR MENDES, j. 11/10/2005, 2 ${ }^{\mathrm{a}}$ T., DJ 27/10/2006, p. 64).
} 


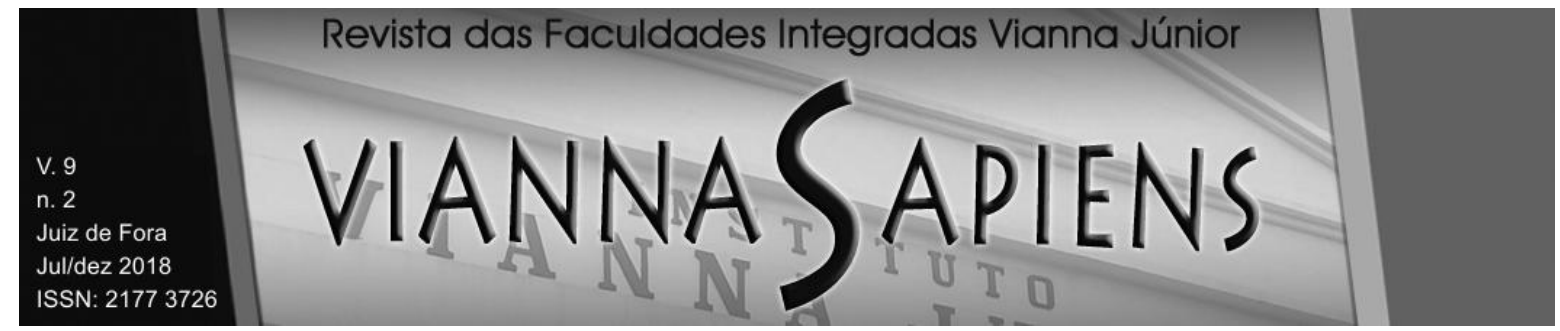

Com base nesta análise, evidencia-se que não há motivos para não aplicação dos Direitos Fundamentais nas relações privadas, tendo em vista que não só o estado como também o próprio particular pode atentar contra direitos. Posto isso, tal tese é a que melhor reflete a garantia e eficácia dos Direitos Fundamentais.

\section{CONSIDERAÇÕES FINAIS}

A aplicação dos direitos fundamentais nas relações entre particulares enseja ainda inúmeras controvérsias na doutrina e jurisprudência brasileira.

O atual momento histórico tem por característica a constitucionalização de todo e qualquer direito, ou seja, é impossível que as relações jurídicas privadas se mostrem incoerentes com os princípios constitucionais.

Desta forma, uma vez expostas todas as características, dimensões, e definições dos Direitos Fundamentais, pode-se concluir que com o passar dos anos a evolução de tais direitos se mostrou clara no tocante à eficácia horizontal, onde sua intensidade de aplicação deverá ser proporcionalmente à situação de desigualdade entre o indivíduo que teve seu direito violado e o ente privado causador desta violação.

Nesse sentido, não cabe ao Estado apenas respeitar, mas também resguardar a observância do regular cumprimento das normas de direitos fundamentais por todos aqueles potencialmente capazes de violar tais Direitos.

Por fim, acerca da discussão da aplicabilidade direta ou indireta dos direitos fundamentais, verifica-se a necessidade da fiel prestação da função típica legislativa, que, por intermédio de leis infraconstitucionais, aprimore a aplicação de Direitos Fundamentais, colaborando com a aplicação da lei ao caso concreto. 


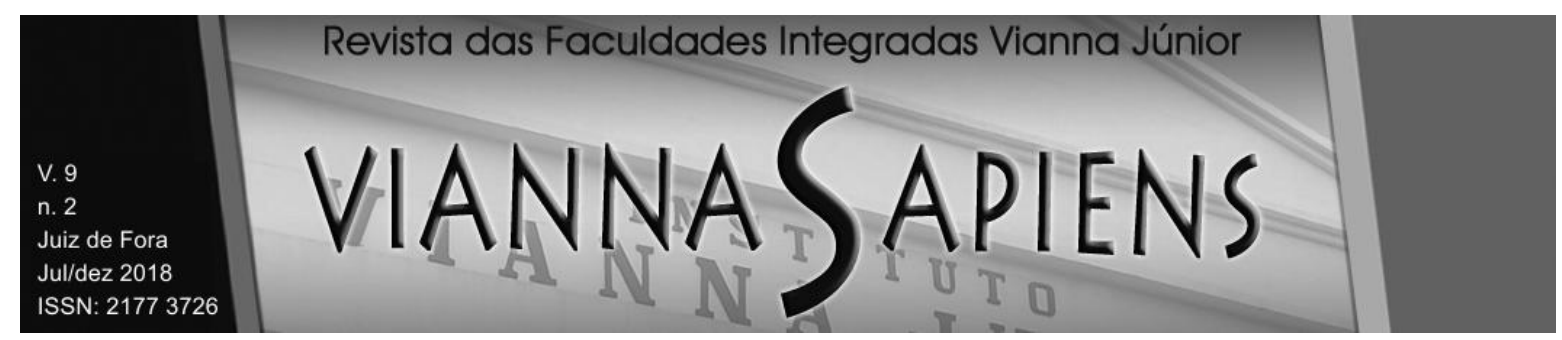

\section{REFERÊNCIAS}

ALVES, Cristiane Paglione. A eficácia horizontal dos direitos fundamentais. Disponível em: http://www.egov.ufsc.br/portal/conteudo/efic\%C3\%A1cia-horizontaldos-direitos-fundamentais. Acesso: 15 de nov. 2018.

AMARAL, Karina. Os direitos fundamentais na Constituição Portuguesa de 1976: a eficácia dos direitos de liberdade e dos direitos sociais. Direito, Estado e Sociedade, n.37, p.6 a 26, jul/dez 2010.

ANDRADE, J. C. Vieira de. Os direitos fundamentais na Constituição Portuguesa de 1976, 2. ed.. Editora Livraria Almedina, 2001.

ALEXANDRINO, José de Melo. Direitos Fundamentais. Introdução Geral. Estoril: Princípia, 2007.

BERNARDES, Juliano Taveira., FERREIRA, Olavo Augusto Vianna Alves. Direito Constitucional. Teoria da Constituição. 5를. SALVADOR: JusPodivm, 2015.

BRASIL, Constituição Federal de 1988. Constituição da República Federativa do Brasil. Texto Constitucional promulgado em 5 de outubro de 1988, Brasília. Disponível em http://www.planalto.gov.br/ccivil 03/constituicao/ConstituicaoCompilado.htm.

BONAVIDES, Paulo. Curso de Direito Constitucional, 25.ed. São Paulo: Malheiros, 2010.

. Curso de Direito Constitucional. 19.ed. São Paulo: Malheiros, 2006.

CANOTILHO, J. J. Gomes. Direito Constitucional e teoria da constituição. 3. ed., Coimbra: Almedina, 2002.

LENZA, Pedro. Direito Constitucional Esquematizado. 12.ed. São Paulo: Saraiva, 2009. 


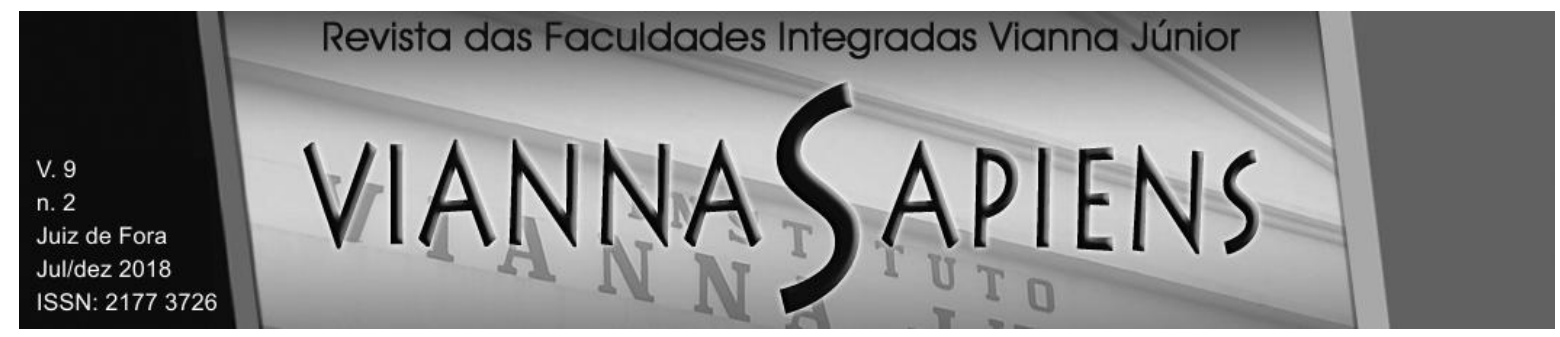

MORAES. Alexandre de.- Direitos Humanos Fundamentais: teoria geral, comentários aos arts. $1^{\circ}$ a $5^{\circ}$ da Constituição da República Federativa do Brasil, doutrina e jurisprudência. 3. ed., São Paulo: Atlas, 2000.

MORAES, Alexandre de. Constituição do Brasil Interpretada e Legislação Constitucional. 7. ed. Atual. São Paulo. Atlas, 2007

SARLET, Ingo Wolfgang. A eficácia dos direitos fundamentais. 6. ed. Porto Alegre: Livraria do Advogado, 2006.

SARMENTO, Daniel. Direitos fundamentais e relações privadas. 2. ed. Rio de Janeiro: Lúmen Júris, 2010.

SILVA, José Afonso da. Curso de Direito Constitucional Positivo. São Paulo: Malheiros, 2003.

TÂMEGA, Bruna Carolina. BASSOLI, Marlene Kempfer. A concretização dos Princípios Constitucionais pelo Poder Judiciário. Ano 1. Vol. 3. Disponível em: http://egov.ufsc.br/portal/sites/default/files/anexos/31848-36994-1-PB.pdf.

Recebido em 27/11/2018

Publicado em 21/12/2018 